\title{
DURAÇÃO DA ESTAÇÃO CHUVOSA E OCORRÊNCIA DE VERANICOS NA BACIA DO RIO PARANAÍBA
}

\author{
Mariana Mendes Silva ${ }^{1}$ \\ Vanderlei Oliveira Ferreira ${ }^{2}$
}

Resumo: Este artigo procura contribuir para demarcação do início e fim da estação chuvosa e avaliação da frequência e intensidade de veranicos na bacia hidrográfica do rio Paranaíba, que abrange áreas dos estados de Goiás, Minas Gerais, Distrito Federal e Mato Grosso do Sul. A compreensão de tal assunto é particularmente útil para entendimento do ritmo pluviométrico da bacia, podendo subsidiar o planejamento e gestão de atividades econômicas vulneráveis em relação ao ritmo de oferta hídrica. Recorreu-se às séries históricas de vinte e dois postos pluviométricos da Agência Nacional de Águas (ANA), correspondentes ao período 1973-2011 (38 anos). Para delimitar a estação chuvosa foram adotados critérios baseados na quantidade e continuidade das chuvas. No caso dos veranicos, baseou-se em somatórios de dias interiores ao período chuvoso sem precipitações ou que as mesmas tenham sido inferiores ou iguais à metade da evapotranspiração diária. Constatou-se que o período chuvoso ocorre, em média, de 28 de outubro a 02 de abril, embora existam especificidades, destacando-se Brasília e seu entorno e o leste da bacia. Quanto aos veranicos, os meses mais preocupantes são janeiro e fevereiro, pois, apesar de receberem totais pluviométricos mensais mais expressivos, registram o maior número de eventos, especialmente mais longos.

Palavras-chave: Variabilidade Pluviométrica; Ano Hidrológico; Eventos de Estiagens.

\section{DURATION OF THE RAINY SEASON AND OCCURRENCE OF DRY SPELLS IN THE BASIN OF THE PARNAÍBA RIVER}

\begin{abstract}
This article search contribute for demarcation of the beginning and end of the rainy season and evaluation of the frequency and intensity of dry spells in the Basin of the Parnaiba River, which covers areas of the states of Goiás, Minas Gerais, Distrito Federal and Mato Grosso do Sul. The understanding of this subject is particularly useful for the understanding of the rainfall rhythm of the basin, being able to subsidize the planning and management of economic activities vulnerable in relation to the rhythm of water offer. Was used the historical series of twenty-two rain gaugesof the Agência Nacional de Águas (ANA), corresponding to the period 1973-2011 (38 years).To delimit the rainy season was adopted criterias with base in the amount and continuity of the rainfalls. In the case of dry spells was based on summation of days interiors of the rainy season without precipitations or that they have been equals or lower to half the daily evapotranpiration. It was found that the rainy season occurs, on average, from 28 October to 02 April, although there are specificities,
\end{abstract}

1. Mestre em Geografia, professora substituta do Instituto Federal de Educação, Ciência e Tecnologia do Triângulo Mineiro - IFTM (marianamendes_01@yahoo.com.br).

2. Doutor em Geografia, professor da Universidade Federal de Uberlândia - UFU (vanderlei@ig.ufu.br). 
highlighting Brasilia and its surroundings and the eastern basin. As for the dry spells, the most worrisome months are January and February, because, despite receiving rainfall totals monthly more expressives, recorded the highest number of events, especially more long.

Key words: Rainfall variability; Hydrological year; Drought events.

\section{INTRODUÇÃO}

A variabilidade pluviométrica interfere diretamente na disponibilidade e demanda hídrica, determinando a ocorrência de situações críticas para a sociedade e para o ambiente. Existe forte relação entre volume, frequência e intensidade da pluviosidade com a disponibilidade hídrica superficial e subterrânea, já que a chuva representa a fonte primária da maior parte da água doce terrestre.

Diante da importância econômica e ambiental do regime pluviométrico, a presente pesquisa adotou a bacia hidrográfica do rio Paranaíba como unidade territorial de um estudo com o intuito de demarcar o início e o fim da estação chuvosa e avaliar a frequência e intensidade dos veranicos. A área de estudo compreende $25,4 \%$ da região hidrográfica do Paraná, sendo considerada a segunda maior unidade hidrográfica da mesma. Cerca de $65 \%$ de sua área está inserida no estado de Goiás, 30\% em Minas Gerais, 3\% no Distrito Federal e 2\% no Mato Grosso do Sul (Figura 1).

A bacia do Paranaíba possui características climáticas diversificadas, devido à sua altimetria, sua posição geográfica e, principalmente, à atuação dos sistemas atmosféricos dinâmicos, que condicionam direta ou indiretamente o regime pluvial. A Zona de Convergência do Atlântico Sul (ZCAS) e as Frentes Frias são as principais responsáveis pela precipitação. Já o Anticiclone Subtropical do Atlântico Sul e o Vórtice Ciclônico de Ar Superior ocasionam a maioria dos períodos de estiagem (MINUZZI et al., 2007, p. 339). Em termos genéricos, o clima da bacia apresenta duas estações bem definidas: uma concentra grande parte das precipitações anuais (estação chuvosa) e outra um decréscimo ou ausência de precipitações (estação seca). 


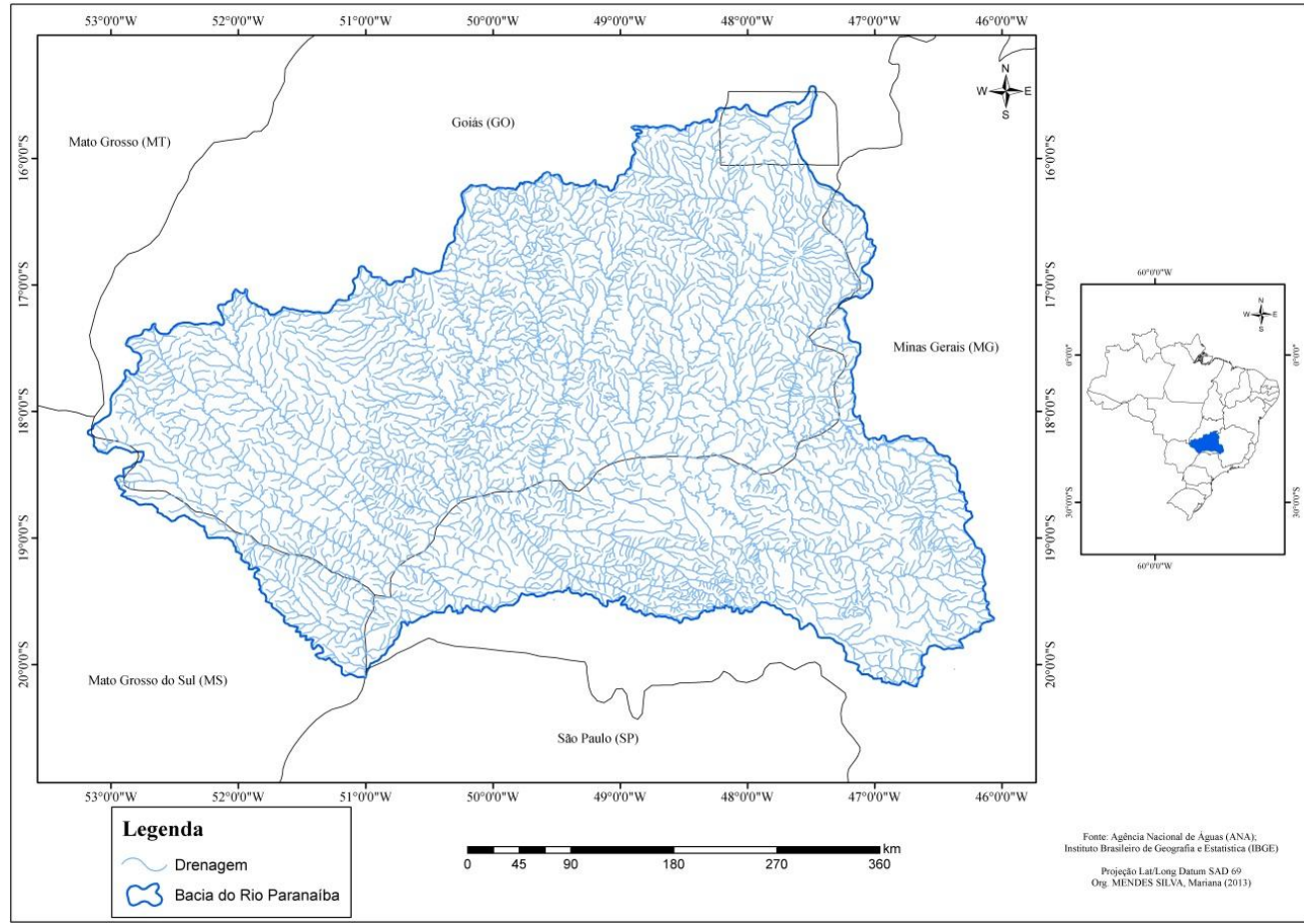

Figura 1: Mapa de localização da bacia do rio Paranaíba.

A pesquisa focou o período chuvoso, pois é nele que ocorre grande parte do total das chuvas anuais, que se concentram entre os meses de outubro a março. Isso faz com que grande parte das atividades agrícolas seja desenvolvida nesta estação, já que é quando acontecem quantidades de chuvas significativas do ponto de vista da reposição e armazenamento de água no solo.

O objetivo principal do estudo foi demarcara estação chuvosa e os intervalos temporais dentro da mesma em que não há precipitações significativas (veranicos). Segundo Sousa e Peres (1998), apesar de nos Cerrados a precipitação total no período chuvoso ser suficiente para o desenvolvimento da agricultura é preciso avaliar os episódios de veranicos, que são caracterizados muitas vezes por breves períodos de estiagem, mas que de forma acentuada podem prejudicar o desenvolvimento das culturas, acarretando perdas na produção, dependendo do estágio de desenvolvimento das plantas. A previsão da ocorrência dos veranicos pode ajudar o agricultor se organizar em relação às suas decisões, incluindo a possibilidade de recorrência à irrigação para minimizar as consequências da ausência de chuvas. 


\section{MATERIAIS E MÉTODO}

\section{Seleção dos postos pluviométricos}

A pesquisa contou com dados diários da rede de monitoramento da Agência Nacional de Águas (ANA). Dentre 214 postos pluviométricos avaliados inicialmente, 121 atendiam aos critérios da pesquisa. Entretanto, após espacialização, procurou-se criar uma distribuição relativamente uniforme dos mesmos no território da bacia, resultando na delimitação de 22 (Tabela 1 e Figura 2), considerados suficientes e viáveis do ponto de vista do tratamento estatístico e geração das informações para execução dos procedimentos metodológicos. Os postos pluviométricos selecionados contam com um intervalo de dados de no mínimo 30 anos.

\begin{tabular}{|c|c|c|c|c|c|c|c|}
\hline uF & Municlpio & $\begin{array}{l}\text { NOME DO } \\
\text { POSTO }\end{array}$ & $\begin{array}{l}\text { N2 DO } \\
\text { POSTOO }\end{array}$ & LAT. & LONG. & ALT. (M) & $\begin{array}{l}\text { PER/DDO DE } \\
\text { DADOS } \\
\text { DISPON/VEIS }\end{array}$ \\
\hline MG & Sante Julians & Sente dulieng & 1947001 & $-19,32$ & $-47,93$ & 990 & $1941-2011$ \\
\hline MG & Estreis do Sul & Estelo do Sul & 1947001 & $-18,74$ & 47,59 & 451 & $1944-2011$ \\
\hline MG & lbie & loib & 1945004 & $-19,43$ & 45,34 & 855 & $1945-2011$ \\
\hline MG & Petrocinio & $\begin{array}{l}\text { Charquesde do } \\
\text { Petrocinio }\end{array}$ & 1945002 & $-18,93$ & 46,97 & 960 & $1967-2011$ \\
\hline MG & Ituivtebs & Ifuivtebs 1 & 1949000 & $-18,94$ & 49,45 & 963 & $1957-2011$ \\
\hline MG & Prete & $\begin{array}{l}\text { Fesende Buriti } \\
\text { do Prete }\end{array}$ & 1949002 & $-19,35$ & 49,18 & 517 & $1958-2011$ \\
\hline Ma & Secramento & Desemboque & 2047037 & $-20,01$ & 47,02 & 950 & $1971-2011$ \\
\hline GO & Inhumes & Inhumes & 1549005 & $-16,35$ & 49,90 & 747 & $1990-2011$ \\
\hline Go & Alexánis & $\begin{array}{l}\text { Ponte AnÉpolis- } \\
\text { Bresilis }\end{array}$ & 1549001 & $-16,08$ & 48,51 & 1087 & $1958-2011$ \\
\hline GO & Mineiros & Ponte do Cedro & 1752003 & $-17,38$ & $-52,60$ & 690 & $1971-2011$ \\
\hline GO & Jatai & Ponte Rio Doce & 1751001 & $-17,85$ & $-91,40$ & 758 & $1972-2011$ \\
\hline GO & Pareúne & $\begin{array}{l}\text { Fez. Nove do } \\
\text { Turvo }\end{array}$ & 1790001 & $-17,08$ & $-90,29$ & 909 & 1971-2011 \\
\hline GD & Goiatubs & Fazends Alianģa & 1890001 & $-18,10$ & $-90,03$ & 447 & $1971-2011$ \\
\hline GO & varjäo & $\begin{array}{l}\text { Ferende Bos } \\
\text { Vists }\end{array}$ & 1749001 & $-17,11$ & 49,69 & $5: 8$ & $1971-2011$ \\
\hline GO & Aporé & Campo Alegre & 1851001 & $-18,52$ & $-91,09$ & 670 & $1972-2011$ \\
\hline GO & Buriti Alegre & Corumbesul & 1849007 & $-18,24$ & 48,85 & 547 & $1972-2011$ \\
\hline Go & rtaje & Itaje & 1951001 & $-19,14$ & $-91,53$ & 496 & $1972-2011$ \\
\hline Go & Critienópolis & Cristienópolis & 1749000 & $-17,20$ & 48,72 & 829 & $1973-2011$ \\
\hline 60 & Turvánis & Turvánis & 1590003 & $-16,51$ & $-90,13$ & 700 & $1973-2011$ \\
\hline Go & Cristeline & Cristalins & 1547002 & $-16,76$ & 47,51 & 1239 & $1973-2011$ \\
\hline DF & Brasilis & Bresilia-01s & 1547004 & $-15,79$ & 47,92 & 1160 & $1952-2011$ \\
\hline DF & Brasilis & $\begin{array}{l}\text { BrozllOndlo } \\
\text { (Quedre 18) }\end{array}$ & 1549000 & $-15,57$ & 48,22 & 1105 & 1973-2011 \\
\hline
\end{tabular}

Tabala 1: Informações dos postos pluviométricos selecionados para a pesquisa Fonte: ANA (2012).

Org. MENDES SILVA, M. (2012). 
MARIANA MENDES SILVA, VANDERLEI OLIVEIRA FERREIRA

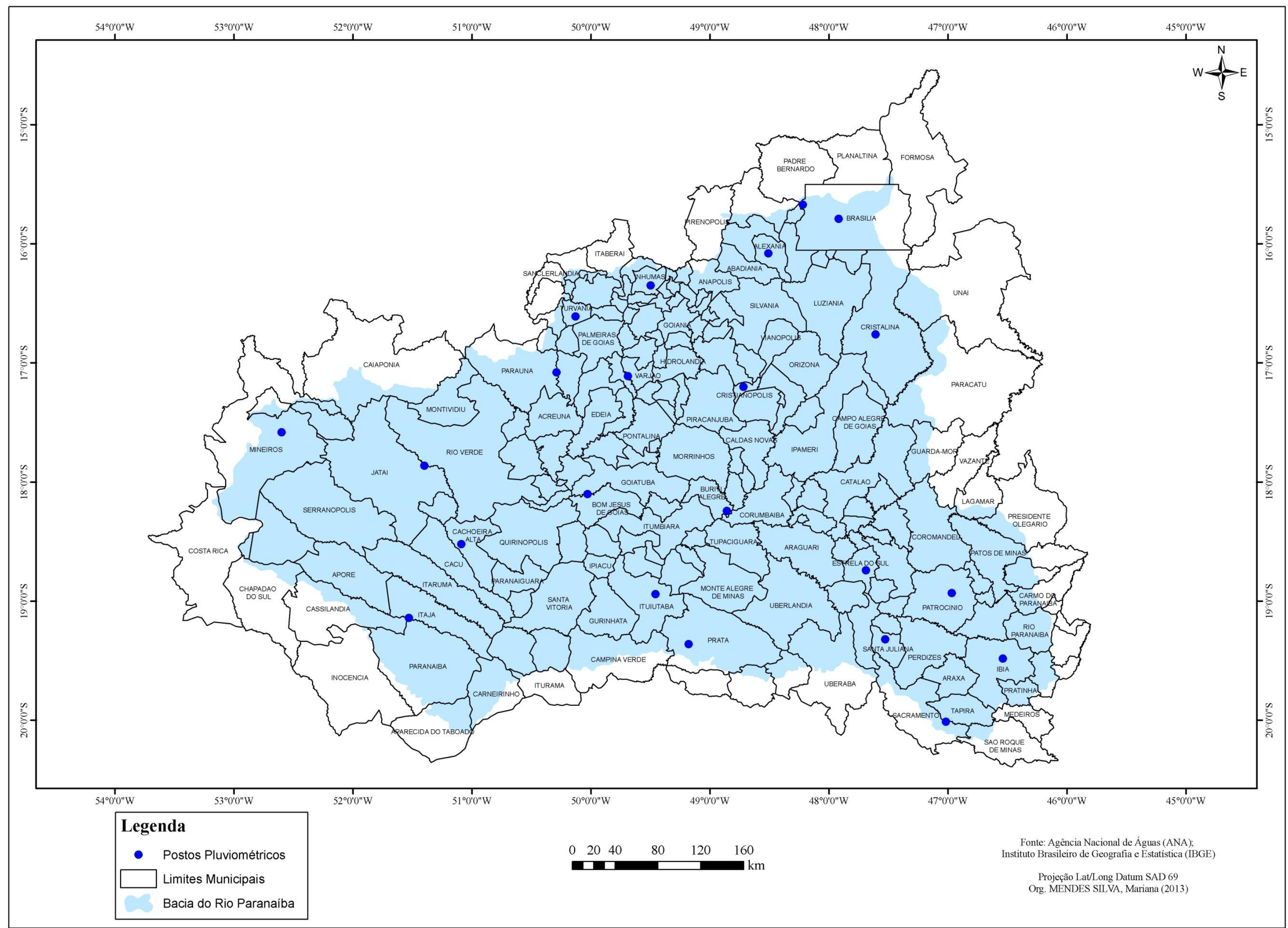

Figura 2: Localização dos vinte e dois postos pluviométricos selecionados para a pesquisa. 


\section{Determinação da duração da estação chuvosa}

As datas de início e fim da estação chuvosa têm sido obtidas por diversos critérios. No presente caso utilizou-se de dados de precipitações diárias para a aplicação das metodologias de Sansigolo (1989) e Assunção (2013), baseadas nas quantidades e continuidade das chuvas. Assim, foram observados para delimitação do início do período chuvoso, os seguintes critérios:

- Ocorrência de $20 \mathrm{~mm}$ de chuva acumulados em um ou dois dias consecutivos, pois essa quantidade é suficiente para que ocorra a germinação de sementes de várias espécies;

- Não ocorrência de 10 dias secos ou com chuvas insignificantes do ponto de vista da reposição hídrica do solo nos 30 dias seguintes. Dia chuvoso é aquele que a precipitação é igual ou maior que a evapotranspiração (ETP) diária; e,

- Ocorrência do fim do déficit hídrico no referido mês, começo da reposição de água no solo, seguido de excedente hídrico.

Caso até o mês de dezembro não ocorresse nenhuma das condições anteriores, considerou que esse mês faz parte do período chuvoso, mesmo que não atenda às exigências e que ocorram veranicos.

Para delimitar o fim da estação chuvosa foram consideradas as seguintes condições:

- Sequência de 10 dias consecutivos sem precipitações ou que as mesmas não superem a ETP diária;

- Se no mês de março ocorrer totais pluviométricos acumulados abaixo da ETP mensal, mesmo com chuvas bem distribuídas, consideram-se os períodos de baixas precipitações como veranicos; e,

- O mês de maio só será considerado da estação chuvosa caso em abril as chuvas ocorram abundantemente e suficientes para repor a ETP mensal. Se isso não ocorrer as chuvas abundantes em maio são consideradas chuvas isoladas.

O mês de fevereiro é considerado do período chuvoso mesmo que haja veranicos.

Devido à necessidade dos dados de evapotranspiração para delimitação do início e fim da estação chuvosa e com o intuito de caracterizar o regime pluviométrico da bacia 
foram calculados os balanços hídricos climatológicos conforme Thornthwaite e Matter (1955) através de uma planilha do software Microsoft Excel, elaborada por Rolim et al. (1998).

Adotou-se a Capacidade de Água Disponível (CAD) igual a $100 \mathrm{~mm}$ para todos os postos pluviométricos. A latitude foi transformada para décimos de graus utilizando-se junto a esse valor o sinal de negativo para indicar que os locais dos postos estão no hemisfério Sul. As temperaturas foram estimadas por meio de uma equação linear múltipla que leva em consideração dados de temperatura média do ar (variável dependente), latitude, longitude e altitude (variáveis independentes), pois se observou a insuficiência de dados observados em estações meteorológicas para uma adequada caracterização térmica.

Após a demarcação da estação chuvosa analisou-se os valores extremos do início do período de chuvas para demonstrar a ocorrência em alguns anos de possíveis "anomalias". Assim, as estações chuvosas foram classificadas conforme disposto na Tabela 2, adaptado da metodologia de Minuzzi (2006, p. 43).

\begin{tabular}{|c|l|l|}
\hline CLASSE & \multicolumn{1}{|c|}{ CLASSIFICAÇÃO } & \multicolumn{1}{c|}{ DESCRIÇÃO } \\
\hline I & Muito precoce & $\begin{array}{l}\text { A partir de 20 dias anteriores à data média do IPC dos anos } \\
\text { normais }\end{array}$ \\
\hline II & Precoce & $\begin{array}{l}\text { A partir de 10 dias anteriores à data média do IPC dos anos } \\
\text { normais }\end{array}$ \\
\hline III & Normal & $\begin{array}{l}\text { 10 dias antes e 10 dias após a data média do IPC dos anos } \\
\text { normais }\end{array}$ \\
\hline IV & Tardia & $\begin{array}{l}\text { A partir de 10 dias posteriores à data média do IPC dos anos } \\
\text { normais }\end{array}$ \\
\hline V & Muito tardia & $\begin{array}{l}\text { A partir de 20 dias posteriores à data média do IPC dos anos } \\
\text { normais }\end{array}$ \\
\hline
\end{tabular}

Tabela 2: Subdivisões de classes referentes ao início do período chuvoso (IPC), tendo como referência a data média dos anos normais.

Fonte: MINUZZI (2006)

\section{Identificação e caracterização de veranicos}

Utilizou-se a metodologia de Assunção e Leitão Júnior (2006) que se baseia na identificação de intervalos de dias sem precipitações dentro da estação chuvosa, ou que as chuvas tenham sido inferiores ou iguais à metade da ETP diária, devido à irrelevância destas frente à capacidade de reposição de água no solo.

Essa metodologia leva em conta também que em situações de precipitações superiores à metade da ETP diária e inferiores a 1,5 vezes a ETP diária, desconta-se um 
dia no total dos intervalos sem precipitações (veranicos). O período de estiagem somente será considerado terminado caso ocorra uma precipitação superior a 1,5 vezes a ETP diária, pois já são chuvas que representam alterações no ambiente sob o ponto de vista da disponibilidade hídrica.

Os veranicos identificados foram inseridos em uma tabela, incluindo a frequência e probabilidade de acontecimento dos mesmos. Classificou-se os veranicos em inapreciáveis, com 6 dias de duração; fracos, de 7 e 8 dias; médios, de 9 a 12 dias; fortes, de 13 a 18 dias; e muito fortes, maiores que 18 dias.

\section{RESULTADOS E DISCUSSÕES}

\section{Análise do início e fim da estação chuvosa}

A bacia hidrográfica do rio Paranaíba possui características climáticas relativamente diversificadas devido às variações altimétricas e sua posição quanto à atuação dos sistemas atmosféricos. É comumente caracterizada como apresentando um regime tipicamente tropical, com duas estações bem definidas, uma chuvosa e outra seca.

A pluviosidade anual apresenta maiores médias na porção leste/nordeste da bacia e na porção sudeste, que compreendem áreas de cabeceiras (altitudes mais elevadas e de topografia plana/suavemente ondulada). Também no baixo curso do rio Paranaíba a pluviosidade é relativamente elevada devido à penetração facilitada de sistemas atmosféricos de sul, especialmente incursões de frentes polares. As Figuras 3 e 4 apresentam os mapas de altimetria e precipitação média anual, respectivamente.

O período de maior precipitação ocorre entre os meses de outubro a março. Em outubro começam a aumentar as chuvas até chegar ao ápice do período chuvoso, que corresponde aos meses de dezembro e janeiro (Gráfico 1). Por outro lado, a partir de fevereiro há nítida diminuição das precipitações até iniciar a estação seca propriamente dita. 


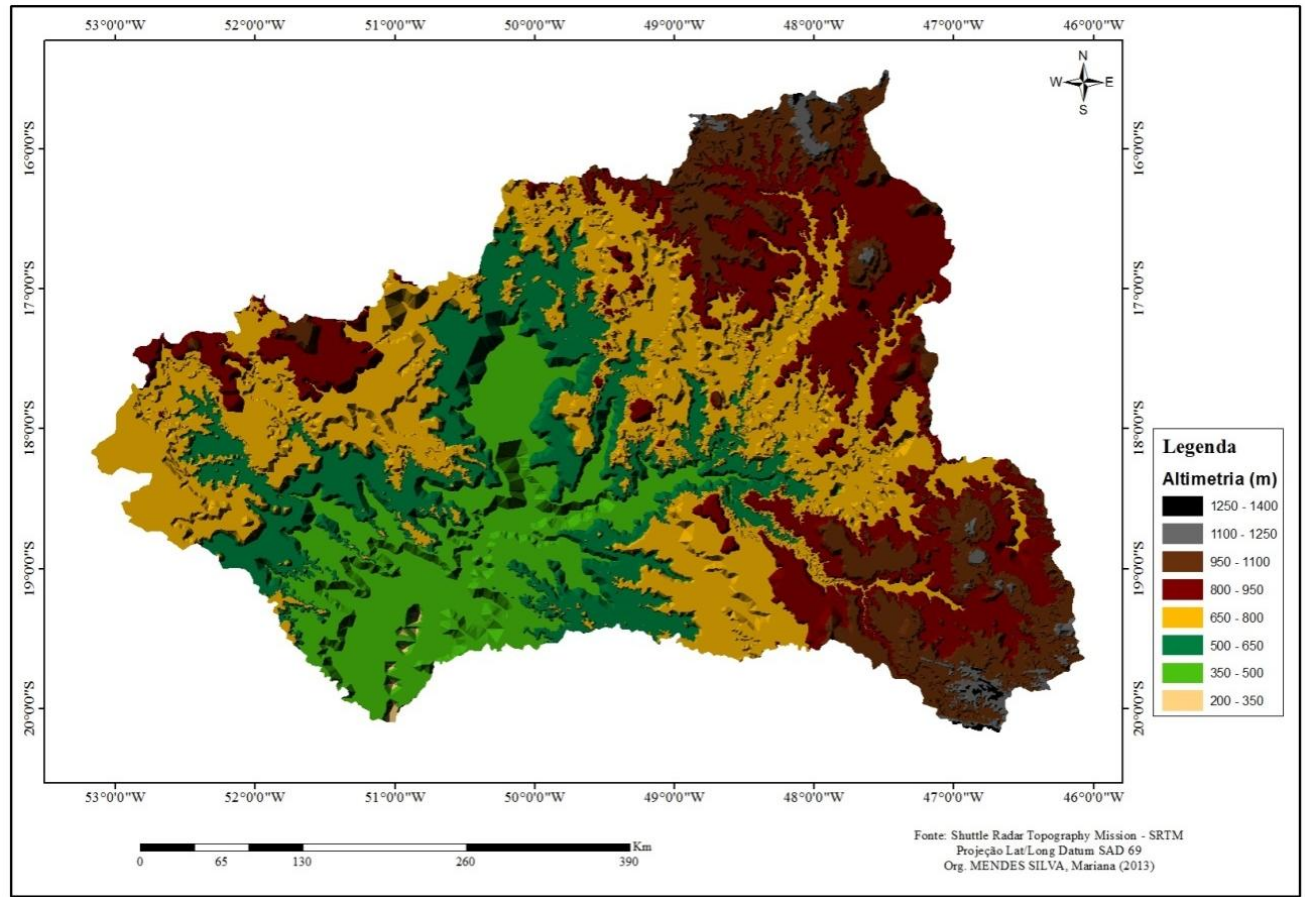

Figura 3: Mapa altimétrico da bacia do rio Paranaíba.

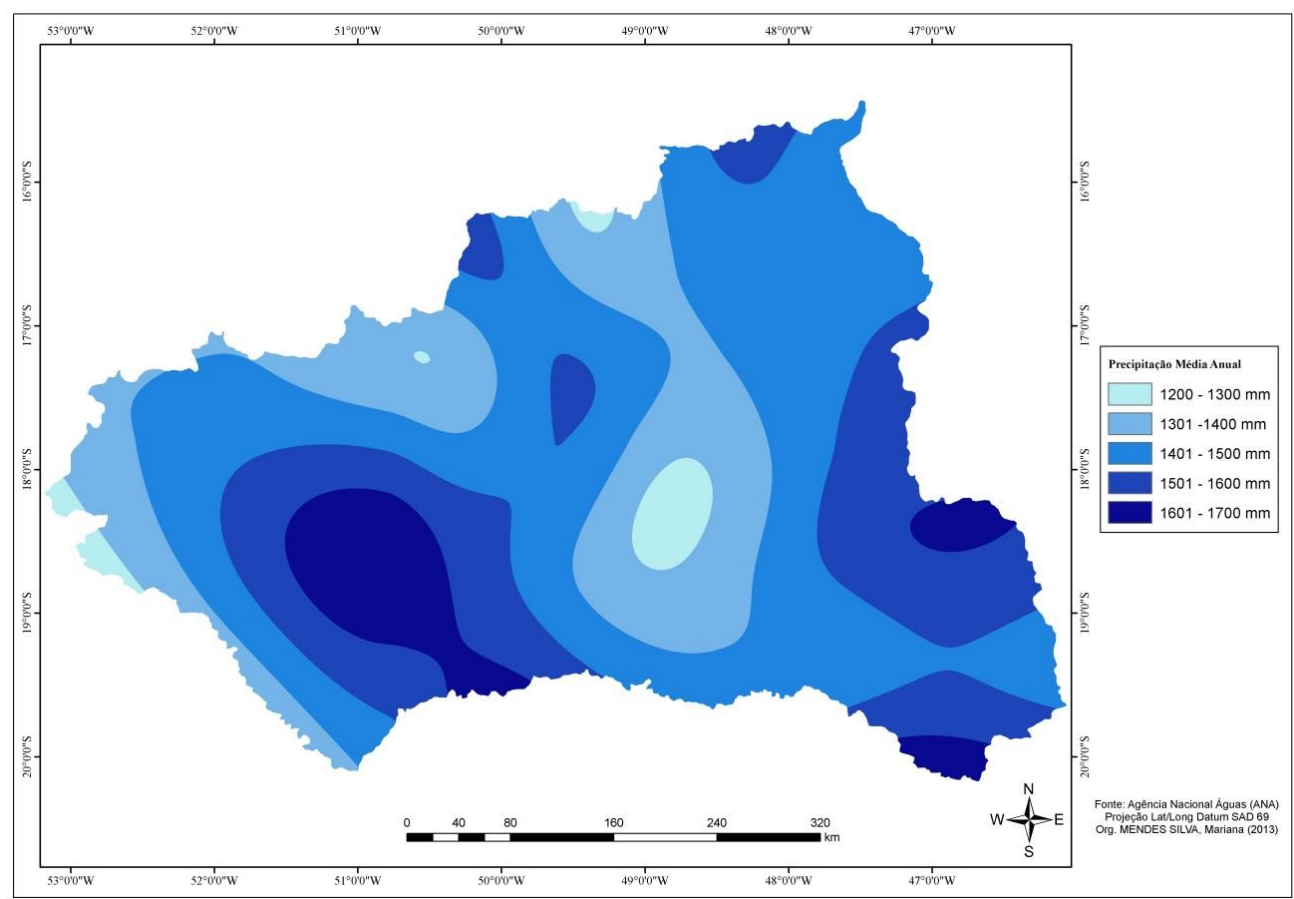

Figura 4: Mapa de precipitação média anual da bacia do rio Paranaíba. 


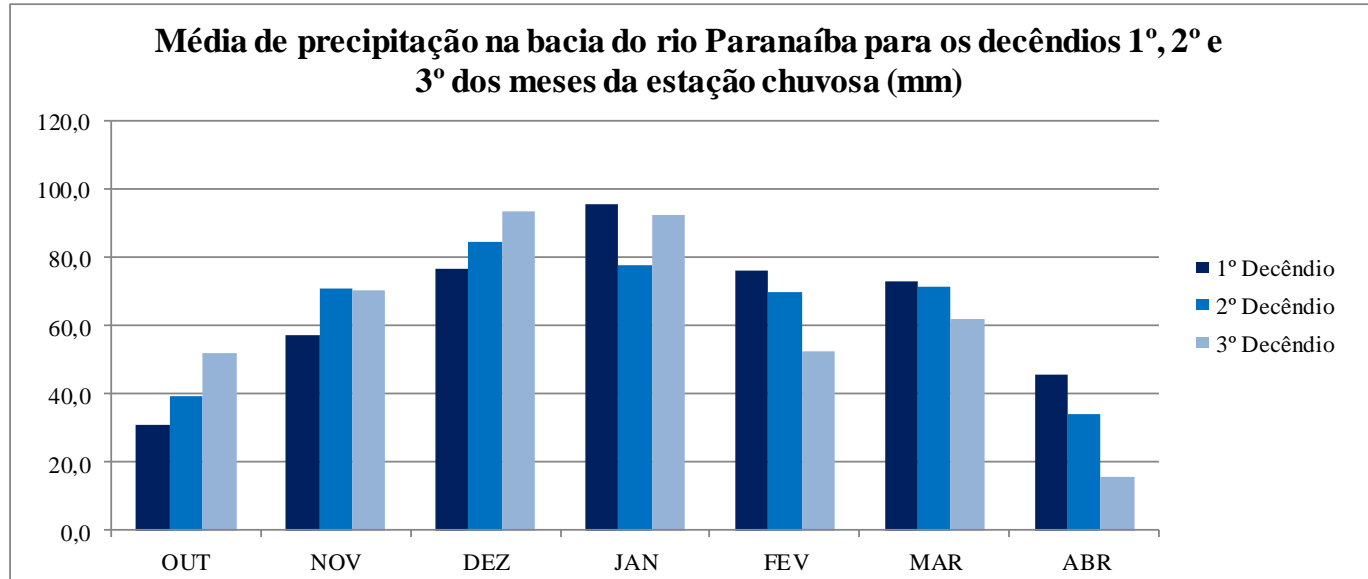

Gráfico 1: Média de precipitação nos decêndios dos meses do período chuvoso na bacia do rio Paranaíba.

Org. MENDES SILVA, M. (2013).

Constatou-se que, em média, o início da estação chuvosa na bacia ocorre em 28 de outubro e a média do término acontece em2 de abril, durando mais ou menos 156 dias (Tabela 3).

\begin{tabular}{|c|c|c|c|c|}
\hline UF & POSTOS PLUVIOMÉTRICOS & $\begin{array}{l}\text { MÉDIA DO INÍCIO } \\
\text { DA ESTAÇÃO } \\
\text { CHUVOSA }\end{array}$ & $\begin{array}{c}\text { MÉDIA DO FIM DA } \\
\text { ESTAÇÃO } \\
\text { CHUVOSA }\end{array}$ & $\begin{array}{c}\text { DURAÇÃO DA } \\
\text { ESTAÇÃO } \\
\text { CHUVOSA } \\
\end{array}$ \\
\hline MG & Charqueado do Patrocínio & 25/out & 29/mar & 155 \\
\hline MG & Desemboque & 21/out & $09 / a b r$ & 170 \\
\hline MG & Estrela do Sul & 25/out & 29/mar & 155 \\
\hline MG & Faz. Buriti do Prata & 28/out & $28 /$ mar & 151 \\
\hline MG & Ibiá & 24/out & $03 / a b r$ & 161 \\
\hline MG & Ituiutaba & 23/out & $01 / a b r$ & 160 \\
\hline MG & Santa Juliana & 22/out & $03 / a b r$ & 163 \\
\hline GO & Campo Alegre & 20/out & $07 / a b r$ & 169 \\
\hline GO & Corumbazul & $11 /$ nov & $17 / \mathrm{mar}$ & 126 \\
\hline GO & Cristalina & 27/out & 07/abr & 162 \\
\hline GO & Cristianópolis & 01/nov & 29/mar & 148 \\
\hline GO & Faz. Aliança & 06/nov & $31 / \mathrm{mar}$ & 145 \\
\hline GO & Faz. Boa Vista & 05/nov & $02 / a b r$ & 148 \\
\hline GO & Faz. Nova do Turvo & 06/nov & $30 /$ mar & 144 \\
\hline GO & Inhumas & 27/out & $08 / a b r$ & 163 \\
\hline GO & Itajá & 08/nov & $25 /$ mar & 137 \\
\hline GO & Ponte Anápolis-Brasília & 29/out & $08 / a b r$ & 161 \\
\hline GO & Ponte do Cedro & 05/nov & $09 / a b r$ & 155 \\
\hline GO & Ponte Rio Doce & 31/out & $02 / a b r$ & 153 \\
\hline GO & Turvânia & 03/nov & $07 / a b r$ & 155 \\
\hline DF & Brasília & $17 /$ out & 09/abr & 174 \\
\hline DF & Brazilândia & 25/out & $05 / a b r$ & 162 \\
\hline MÉDIA & --- & 28/out & $02 / a b r$ & 156 \\
\hline
\end{tabular}

Tabela 3: Média do início e fim da estação chuvosa nos postos pluviométricos da bacia do rio Paranaíba. Org. MENDES SILVA, M. (2013). 
Apesar da tendência relativamente comum da durabilidade da estação chuvosa na bacia, o posto pluviométrico de Corumbazul, localizado no município de Buriti Alegre (GO), tem a menor duração do período chuvoso com apenas 126 dias, podendo constatar que a média do início da estação chuvosa em relação à bacia tem um atraso de 14 dias e o término ocorre 16 dias antes da média geral. Além disso, vale ressaltar que esta localidade tem o menor total anual de precipitações quando comparada aos demais postos analisados.

Outra localidade que também apresenta menor estação chuvosa é Itajá-GO, com 137 dias, sendo que há uma demora de 11 dias no início da estação chuvosa e um término prematuro de 7 dias em relação à média da bacia. Apesar de ser a segunda menor duração da estação chuvosa, a localidade registra um dos maiores totais anuais de precipitação da bacia, com mais de $1490 \mathrm{~mm}$.

Em contrapartida, a maior duração do período de chuvas ocorre em Brasília com 174 dias, iniciando em 17 de outubro e terminando em 09 de abril. Percebe-se que a região no entorno de Brasília, constituída pelos postos de Brazilândia (cidade satélite de Brasília), Ponte Anápolis-Brasília (Alexânia-GO) e Cristalina (Cristalina-GO) também possuem estação chuvosa mais longa (em torno de 160 dias).

Aposto pluviométrico Desemboque, localizado no município de Sacramento-MG, possui o segundo maior total anual de precipitação da área de estudo, com $1.661 \mathrm{~mm}$, tendo o período chuvoso de 170 dias, começando em 21 de outubro e terminando em 09 de abril, ou seja, 7 dias antes da média do início e 7 dias depois da média do término.

O posto Campo Alegre, localizada no município de Aporé (GO), tem o maior total anual de precipitação da bacia do Paranaíba, com quase $1.670 \mathrm{~mm}$. A estação chuvosa dura 169 dias, sendo o início em 20 de outubro (8 dias antes da média geral) e término em 7 de abril (5 dias depois da média geral).

Já Brasília, no Distrito Federal, possui o maior número de acontecimentos de início muito precoce do período chuvoso com 9 ocorrências, em que destacam-se os anos de 1973-1974 quando o período de chuvas começou 34 dias antes da média da bacia (24/09). Em 1977-1978 e 1992-1993 o início ocorreu 33 dias antes da média (25/09). 
Há outras localidades que se destacam por inícios precoces da estação chuvosa. São elas: Campo Alegre, no município de Aporé-GO (57 dias - 2000/2001), Desemboque, no município de Sacramento-MG (54 dias - 1992-1993 e 53 dias - 2009-2010), Charqueada do Patrocínio, no município de Patrocínio-MG (53 dias - 1983-1984), Santa Juliana-MG (52 dias - 1983-1984) e Ibiá-MG (51 dias - 1983-1984 e 50 dias 1976-1977).

Em contrapartida, ocorreram também expressivos acontecimentos de término do período chuvoso muito tardio em relação à média da bacia, como nos postos Fazenda Boa Vista, no município de Varjão-GO (44 dias - 1994/1995); Brasília (44 dias - 20082009); Santa Juliana-MG (42 dias - 1984-1985); Campo Alegre (39 dias - 1994-1995); e Desemboque, no município de Sacramento-MG (35 dias - 1983-1984 e 1991-1992).

Existem casos que a duração da estação chuvosa foi mais longa, ou seja, tanto o início foi precoce quanto o término foi tardio. Esses ocorreram em: Estrela do Sul-MG (47 dias antes e 30 dias depois em 1976-1977); Inhumas-GO (33 dias antes e 25 dias depois em 1973-1974); Brasília (25 dias antes e 26 dias após em 1982-1983); Desemboque, no município de Sacramento-MG (40 dias antes e 35 dias após em 1983-1984); e Campo Alegre, no município de Aporé (GO) (33 dias e 24 dias depois em 1982-1983 e 36 dias antes e 24 dias depois em 1993-1994).

Percebe-se, enfim, que a bacia do rio Paranaíba é propicia para a prática de atividades agrícolas dependentes de chuvas a partir do 3 o quinquídio de novembro ao $4^{\circ}$ quinquídio de março (Quadro 1) e que tenham ciclos de desenvolvimento inferiores há 120 dias para culturas temporárias ou anuais. Isso confirma o fato de que os municípios inseridos na bacia têm grande destaque na produção das monoculturas de soja e milho, sem irrigação. A soja possui dois ciclos principais (ciclo vegetativo e ciclo reprodutivo), que podem variar de 70 a 180 dias, sendo que na bacia do Paranaíba os cultivares disponíveis são de ciclos próximos de 100 dias. Já o milho, tendo em vista o grande número de variedades existentes e o constante processo de aprimoramento genético, incluindo a criação de variedades e híbridos, pode ser plantado em diversos contextos climáticos, desde que ocorra pelo menos $200 \mathrm{~mm}$ de precipitação durante seu ciclo. Neste caso, o problema passa a ser a ocorrência dos veranicos. 


\section{Análise dos Veranicos}

A ocorrência relativamente alta de veranicos pode gerar instabilidade e perdas na produção agropecuária da bacia do Paranaíba. No período analisado (1973-2011) verificou-se 3336 eventos de veranicos (média de 151 por posto pluviométrico). Quando considerado o período de duração dos mesmos, observou-se a seguinte situação: 909 ocorrências, que correspondem há um pouco mais de $27 \%$ do total, que tiveram duração de 6 dias; com intervalo entre 7 a 8 dias aconteceram 1206 vezes (superior a 36\%); veranicos de 9 a 12 dias ocorreram 849 vezes, o equivalente a $25,4 \%$ do total; entre 13 a 18 dias observou-se 286 ocorrências (8,6\%); e apenas 85 eventos (2,5\%) com duração maior que 18 dias.

O fator fundamental na análise dos veranicos não é a quantidade total em cada posto pluviométrico, mas sim, a frequência e probabilidade (\%) de ocorrência dos mesmos em cada mês da estação chuvosa. Neste contexto, os meses mais problemáticos são janeiro e fevereiro, com respectivamente, 605 e 720 acontecimentos. Cabe destacar a frequência relativamente expressiva de tais eventos nos intervalos de 13 a 18 dias e superiores a 18 dias, já que normalmente os veranicos maiores que 13 dias consecutivos podem prejudicar substancialmente as lavouras.

No intervalo entre 13 a 18 dias, no mês de janeiro, ocorreu um total de 72 eventos, ou seja, aproximadamente $12 \%$ de probabilidade e em fevereiro aconteceram 77 , correspondendo a quase $11 \%$ de probabilidade. Em relação aos veranicos superiores a 18 dias, constatou-se que em janeiro ocorreram 30 eventos (o equivalente a $5 \%$ de probabilidade de acontecimento) e em fevereiro ocorreram 43 eventos com $6 \%$ de probabilidade. 


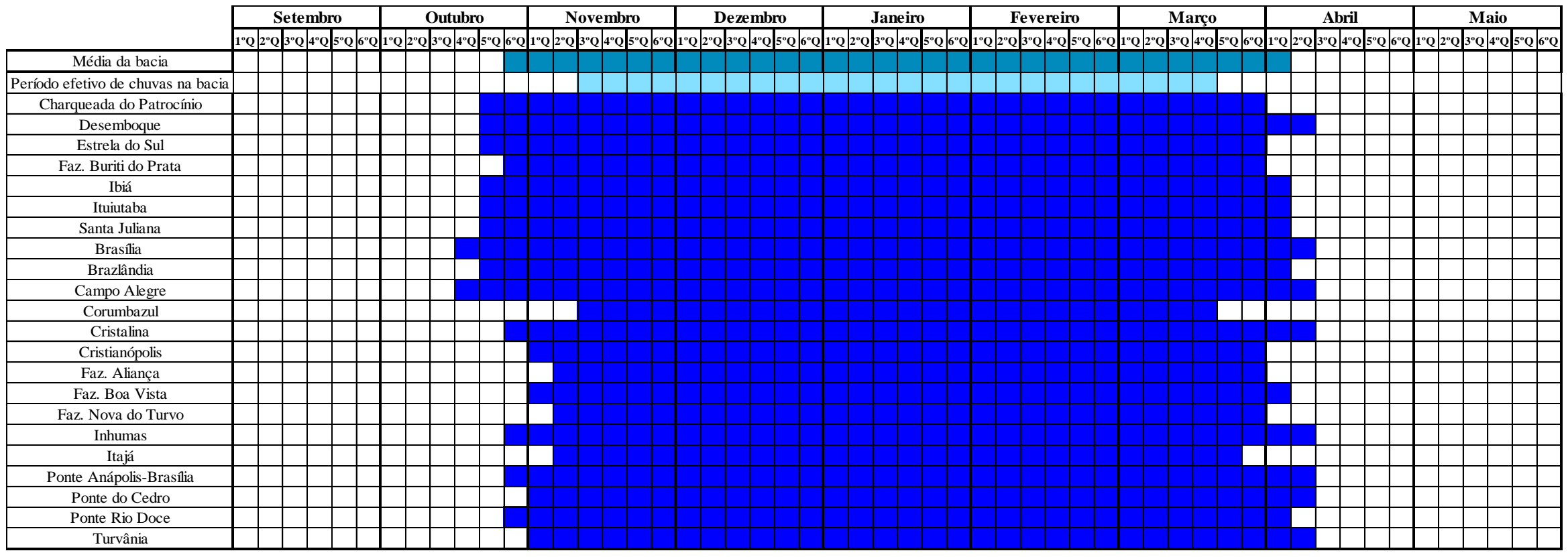

Quadro 1: Oscilação da média do início e fim da estação chuvosa nos postos pluviométricos da bacia do rio Paranaíba. Org. MENDES SILVA, M., 2013 
$\mathrm{Na}$ bacia aconteceram 85 eventos superiores a 18 dias (quase $3 \%$ do total). Em algumas localidades, tais como Charqueada do Patrocínio (Patrocínio-MG), Estrela do Sul-MG, Ituiutaba (MG), Brazilândia (cidade satélite de Brasília), Corumbazul (Buriti Alegre-GO), Cristalina (GO) e Ponte do Rio Doce (Jataí-GO), os veranicos chegaram a durar mais de 30 dias, praticamente descaracterizando a estação chuvosa. Dos 22 postos pluviométricos analisados somente o posto Turvânia-GO não registrou veranicos no intervalo superior a 18 dias. Os postos com maior quantidade de eventos com mais de 18 dias são Corumbazul no município de Buriti Alegre-GO (10 eventos no total neste intervalo) e Estrela do Sul-MG (8 ocorrências). Os postos que possuem as maiores médias de duração de veranicos superiores a 18 dias são: Ituiutaba-MG e Brazilândia-DF com média de 26 dias e Ibiá, Corumbazul (Buriti Alegre-GO), CristalinGO a e Ponte Rio Doce (Jataí-GO) com 24 dias em média.A localidade que apresenta uma das menores quantidades de veranicos com duração superior a 18 dias é Brasília com 3 ocorrências e média de duração de 19 dias.

\section{CONCLUSÃO}

A pesquisa partiu do pressuposto de que o estudo da pluviometria, em especial quanto à duração da estação chuvosa e ocorrência de veranicos, é importante para programação e ajuste de práticas agrícolas na bacia do rio Paranaíba. Embora a Zona de Convergência do Atlântico Sul (ZCAS) e as Frentes Polares sejam os sistemas atmosféricos regionais responsáveis pela maior parte das ocorrências de chuvas na região, percebe-se que rugosidade superficial gera influências diferenciadas da dinâmica atmosférica nas alturas pluviométricas nas escalas espaciais inferiores.

O intervalo do 3ㅇ quinquídio de novembro ao 4ำ quinquídio de março representa estatisticamente o período efetivo de chuvas na bacia do rio Paranaíba. Entretanto, há ocorrências de início e fim muito precoce ou muito tardio em todas as localidades analisadas, o que acaba impactando negativamente na produtividade de culturas agrícolas importantes para a região, especialmente soja e milho. 
Os meses de janeiro e fevereiro possuem índices de precipitação mais elevados. Porém, é neles que acontece o maior número de veranicos mais longos (maiores que 13 dias), o que é preocupante e deve merecer atenção nas análises de risco climático.

\section{AGRADECIMENTOS}

À Coordenação de Aperfeiçoamento de Pessoal de Nível Superior (Capes) pelo apoio financeiro.

\section{BIBLIOGRAFIA}

ANA - AGÊNCIA NACIONAL DE ÁGUAS. Sistema de Informações Hidrológicas (Hidroweb). Disponível em:<http://hidroweb.ana.gov.br>. Acesso em: 02 junho de 2012.

ASSUNÇÃO, W. L.; LEITÃO JÚNIOR, A. M. A ocorrência de veranico na Macrorregião do Alto Paranaíba (MG), 1975-2004. In: VII Simpósio Brasileiro de Climatologia Geográfica, 2006, Rondonópolis-MT. Anais. 2006. CD-ROM.

ASSUNÇÃO, W. L. Metodologia para a definição da duração das estações seca e chuvosa na região dos cerrados do Brasil Central - Primeira aproximação. In: 14으 Encontro de Geógrafos de América Latina, 2013, Lima. Anais. 2013.

MINUZZI, R. B. Influência de algumas forçantes climáticas no período chuvoso da região sudeste do Brasil e suas consequências para as culturas da soja e do milho. Tese de Doutorado, Universidade Federal de Viçosa (UFV), Viçosa - MG, 2006.

MINUZZI, R. B.; SEDIYAMA, G. C.; BARBOSA, E. M.; MELO JÚNIOR, J. C. F. Climatologia do comportamento do período chuvoso da Região Sudeste do Brasil. In: Revista Brasileira de Meteorologia, V.22, N.3, 2007, P. 338 - 344.

ROLIM, G. S.; SENTELHAS, P. C.; BARBIERI, V. Planilhas no ambiente EXCEL para os cálculos de balanços hídricos: normal, sequencial, de cultura e de produtividade real e potencial. In: Revista Brasileira de Agrometeorologia, V.6, 1998, P. 133 - 137.

SANSIGOLO, C. A. Variabilidade interanual da estação chuvosa em São Paulo. In: Climanálise, V.4, N.9, 1989, P. 40 - 43.

SOUSA, S. A. V. de; PERES, F. C. Programa computacional para simulação da ocorrência de veranicos e queda no rendimento. In: Pesquisa Agropecuária Brasileira, V. 33, N. 12, 1998, P. $1951-1956$.

THORNTHWAITE, C. W.; MATTER, J. R. The water balance. Publications in Climatology. New Jersey: Drexel Institute of Technology, 1955.

$\begin{array}{cc}\text { Artigo submetido em } & \text { 15/07/2014 } \\ \text { Artigo aceito em } & \text { 21/01/2015 }\end{array}$

